\title{
Reflexión sobre la política como continuidad de la guerra por otros medios
}

Jaime Wheelock Román ${ }^{1}$

Recibido: 14 de octubre de 2013 / Aprobado: 04 de noviembre de 2013

$\mathrm{E}$ debate teórico y la práctica histórica coinciden en que el desarrollo económico sostenido de un país requiere la existencia de incentivos provenientes de un Estado--institucionalmente sólido y fundado en la Ley--, que estimulen a la mayoría de ciudadanos educados a emprender y dedicarse a actividades rentables. ${ }^{2}$

Nicaragua no ha cumplido este desarrollo encontrándose rezagada respecto a sus vecinos. Ha transitado por los diversos modelos de economía y sociedad conocidos sin mayores resultados. Su estructura económica basada en la exportación de productos primarios es la misma de finales del siglo XIX con la mayoría de sus ciudadanos dedicados en el presente a actividades de bajísima rentabilidad.

Por su posición geográfica Nicaragua ha sido afectada por fenómenos naturales y políticos que en parte explican este rezago: Los desastres naturales de gran magnitud han causado numerosas víctimas humanas y la pérdida promedio de 10\% del PIB por año ${ }^{3}$. Asimismo, las intervenciones políticas, económicas y armadas --frecuentes durante el siglo XX--, resultaron en daños humanos y materiales significantes.

\footnotetext{
1 Ha sido Ministro de Agricultura y Reforma Agraria, es Presidente del Instituto para el Desarrollo y la Desarrollo (IPADE). Catedrático e investigador.

2 Douglass North, "Institutions, Institutional Change and Economic Performance", Cambridge University Press, 1990

3 Incer, Wheelock, Cardenal y Rodríguez "Desastres Naturales de Nicaragua", pág. 17, HISPAMER, Managua 2000
}

\section{RESUMEN}

En la Nicaragua de hoy, la política es la continuidad de la guerra por otros medios. Los acuerdos de cese al fuego dejaron intactas las posiciones excluyentes y confrontativas de los bandos en pugna y fueron trasladados al terreno de la política y desde allí hacia las instituciones del Estado. Son afirmaciones en el marco de una reflexión que llama a buscar soluciones a las diferencias políticas, a través del diálogo, la negociación y el consenso.

Palabras clave: Institucionalidad, consensos, reforma electoral, partidos políticos, visión compartida.

\section{ABSTRACT}

In the today's Nicaragua, the politics is war continued by other means. The ceasefire agreements left intact the exclusionary and confrontational positions of the warring factions and were taken to field of politics and from there, to State institutions. In the context of a reflection, these are some statements that call to seek solutions to the political differences through dialog, negotiation and consensus.

Key words: Institutionalism, consensus, electoral reform, political parties, vision. 
Pero estos dos factores exógenos no explican nuestro atraso relativo. En estas notas nos referiremos al grado de solidez institucional del país como factor de estímulo para que los ciudadanos se orienten a dedicar esfuerzos hacia actividades de productividad creciente.

Partimos de la premisa de que concluidas las guerras e insurrecciones que dividieron a las sociedades centroamericanas en las décadas de los 70 y 80, los acuerdos de cese al fuego dejaron intactos al menos de forma clara, en el caso de Nicaragua, las posiciones excluyentes y confrontativas que los bandos en pugna fueron trasladando al terreno de la política y desde allí hacia las instituciones del Estado. Bien puede afirmarse que la política en la Nicaragua de hoy no es otra cosa que la continuidad de la guerra por otros medios.

Las sociedades que han alcanzado niveles superiores de madurez, presentan instituciones sólidas, con vida propia, que dan marco y amparan los derechos individuales básicos del ciudadano: su libertad, igualdad y competencia. Es el caso de los países de Europa Occidental o Canadá. En cambio, cuando las sociedades asientan su estabilidad a través de actores poderosos con intereses propios --sean éstos castas militares, caudillos o líderes religiosos o políticos--, su institucionalidad tiene un grado frágil de madurez, como el caso de Somalia o Haití y los beneficios van hacia élites no a los pueblos. ${ }^{4}$

Tipificar si la sociedad nicaragüense pertenece a tipos superiores, medios o frágiles de institucionalidad carece de sentido. Lo que importa destacar es que cuando una sociedad está alterada por la polarización y la confrontación política, aún cuando viva un clima de paz aparente y tenga al menos formalmente ciertas instituciones, no tendrá las condiciones para que éstas en realidad funcionen y sirvan de estímulo para que los ciudadanos progresen.

Para empezar, Nicaragua se asienta invariablemente en un marco geopolítico regional históricamente inestable. Estamos en el medio de una región turbulenta de hecho. El Salvador tiene una historia de regímenes militares primitivos y violentos, experimentó una guerra en 1969 y una prolongada insurrección armada que concluyó apenas en los años 90. Guatemala registró la revolución de 1948 y golpes de Estado sucesivos a partir de 1954, así como el conflicto armado que se extendió hasta los 90; Honduras experimentó la guerra con el Salvador en 1969 y se ha visto sacudida por golpes militares desde 1960 hasta el último contra el presidente Zelaya en 2010. Costa Rica vivió la revolución armada de 1948 y luego el golpe técnico constitucional reeleccionista asestado por Oscar Arias en 2006. Panamá registra el golpe militar de 1968 e interferencias casi permanentes del mando militar que culminaron en la masacre intervencionista armada de 1989.

El caso mismo de Nicaragua ha sido el de un largo, accidentado y a menudo, inestable proceso de construcción institucional. En 190 años de vida republicana hemos tenido 20 constituciones políticas, cuyos cambios constantes no han proporcionado una dirección y una visión estable a los ciudadanos y las familias. En los últimos treinta años estallaron dos guerras con profundos efectos destructivos y decenas de miles de víctimas. De hecho una proporción muy alta de la juventud, de los ciudadanos en general y de los recursos nacionales se vieron desviados hacia la guerra. En un cuarto de siglo, se experimentó el cambio revolucionario de 1979, el giro conservador de 1990 y otro cambio de timón político y social 16 años después, conduciendo la dirección del país por oscilantes direcciones opuestas. No es una ruta ni un marco lo suficientemente estable para estimular a los ciudadanos a progresar económicamente.

Concluida la guerra por la desmovilización de los grupos de la resistencia en el marco de las elecciones que ganó la UNO en 1990, se abrió el espacio para la paz y la estabilidad duraderas. Tras el cese de fuego se perfilaba la extraordinaria oportunidad de construir con esfuerzos concertados, una nueva y amplia institucionalidad que le diera cabida al esfuerzo de todos los nicaragüenses lo que fue consignado con el llamado del nuevo gobierno a la Reconciliación Nacional. La prueba de fuego para un nuevo e inédito marco de concertación para todo el país, fue el Acuerdo de Transición entre el Gobierno entrante de la UNO y el saliente del FSLN, firmado en abril de 1990. Este acuerdo fue rechazado y denunciado por las posiciones excluyentes de quienes vieron el fin de la guerra como una derrota y para quienes la confrontación

4 William Easterly "Elusive Quest for Growth", MIT Press, 2002 


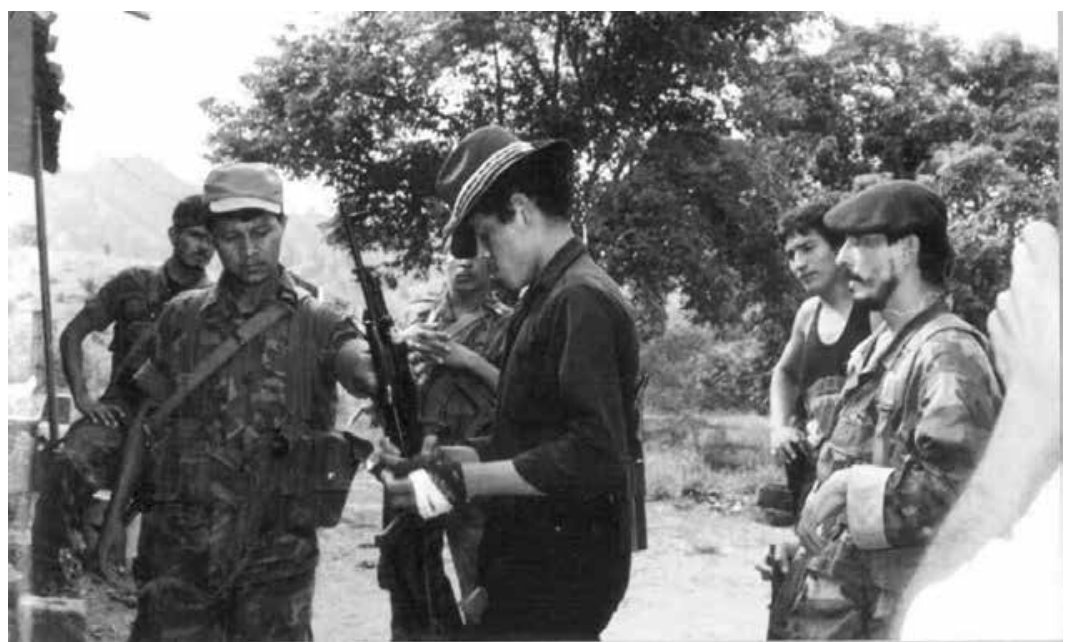

suscritos entre gobierno y gremios laborales, permitió la implementación de los planes de estabilización monetaria y liberalización económica; b) Los acuerdos gobierno-FMI sentaron las bases para favorecer la inversión externa y los acuerdos de libre comercio (CAFTA, Unión Europea con CA); y, c) Los acuerdos entre gobierno, empresa privada y trabajadores desde 2009, han conferido a la economía un marco de armonía y estabilidad favorable al crecimiento. Esta es un área que demuestra cómo la búsqueda de consenso, las soluciones negociadas y el reconocimiento a la participación, dan resultados positivos.

debería continuar sin cuartel hasta la desaparición del contrario. La confrontación por lo mismo se reanudó si bien por otras modalidades.

En ese marco de tensión se han ido colocando las bases de la institucionalidad. Los fundamentos del Estado de Derecho en Nicaragua han sido consagrados por la ley. En los artículos 26, 27, 32, 34, 160, 165, 182, 187 y 189 de la Constitución Política se establecen la igualdad ante la Ley, independencia jurídica de los poderes, los principios de legalidad, publicidad, así como el Control Constitucional. El problema ha sido la falta de cumplimiento de esas normas en los hechos.

Al examinar la funcionalidad y el grado de conformidad con la ley de las diversas instituciones, se observan claras diferencias según el grado de convergencia sobre ellas de los partidos políticos. Donde hay un alto grado de convergencia política y partidaria, las instituciones aparecen disfuncionales; y al contrario donde estos intereses no se cruzan, las instituciones mejoran su funcionalidad.

Funcionalidad en el Área Económica.- No es casual que en áreas donde no están convergiendo las posiciones partidos y sectores políticos que abogan por la continuidad del conflicto y la confrontación, exista una aceptable funcionalidad. Tomemos el caso del área económica nicaragüense donde los actores principales son el gobierno, empresarios y trabajadores. Desde 1990 la economía ha evolucionado favorablemente como producto de un triple consenso: a) Los acuerdos de Concertación Económica y Social de los años 90,
Disfuncionalidad en los Poderes del Estado.- Al contrario, en áreas públicas donde convergen los intereses de los partidos en confrontación, las instituciones han sido incapacitadas para funcionar con normalidad. Este es el caso típico del Consejo Supremo Electoral, cuya actuación en las elecciones de 2011, de acuerdo a los Observadores independientes, se encontró con serias limitaciones: Apropiación por parte de los partidos de aspectos claves de la cedulación; cierre de acceso al padrón electoral; negativa de acreditar a Observación independiente; eliminación de sellos de seguridad; obstáculos en integración de fiscales; publicación de resultados por Centro de Votación y no por Juntas Receptoras de Votos; magistrados con sus cargos vencidos. Todo ello, empañando la credibilidad de las elecciones.

En otros poderes del Estado y órganos Colegiados (Contraloría, Fiscalía, PDH), se han observado parecidos problemas institucionales, derivados de crisis de consenso que los ha convertido en terreno de combate entre los partidos, sectores de prensa y liderazgos excluyentes. Las manifestaciones de disensos e interferencias de origen político-partidarios se materializan en:

a. Tensionamientos por conseguir mayoría partidaria en cada poder del Estado;

b. Parcialidad en procesos de trascendencia nacional, como las contiendas electorales.

c. Actuación de los funcionarios como bancadas partidistas en detrimento de la independencia, profesionalidad y rectitud de las decisiones; 
d. Nombramientos de funcionarios con lógica de bancada;

e. Actuaciones al margen de la Ley expresa;

f. Invasión de funciones entre los poderes (CSE/CSJ/ AN);

g. Integración y designación de miembros de los poderes por medios distintos a lo establecido por la ley;

La institucionalidad en el área Jurídico-política.- Esta área se presenta igualmente alterada por prácticas excluyentes de los partidos. Entre ejemplos de esta alteración se ha señalado entre otros, la anulación de normas constitucionales mediante leyes ordinarias (Leyes Marco); la emisión de decretos ejecutivos habilitando a funcionarios con períodos vencidos a continuar en cargos que sólo la Asamblea Nacional puede sustentar. Asimismo, ante la ausencia de consensos, los propios poderes del estado han actuado en diversas ocasiones en contravención a normas constitucionales.

Otras Areas de Fricción institucional. La confrontación política que afecta principalmente a algunas instituciones como los poderes del Estado, lleva a subvaluar el respeto a otras áreas sensibles del sector público, como las Fuerzas Armadas. En los inicios de los noventas, el PLC intentó, a través de la Alcaldía de Managua, establecer su propia policía paralela, alegando parcialidad de la Policía Nacional. En la actualidad, los Ministerios de Defensa y Gobernación han sido debilitados en sus funciones. Se ha prolongado el periodo de

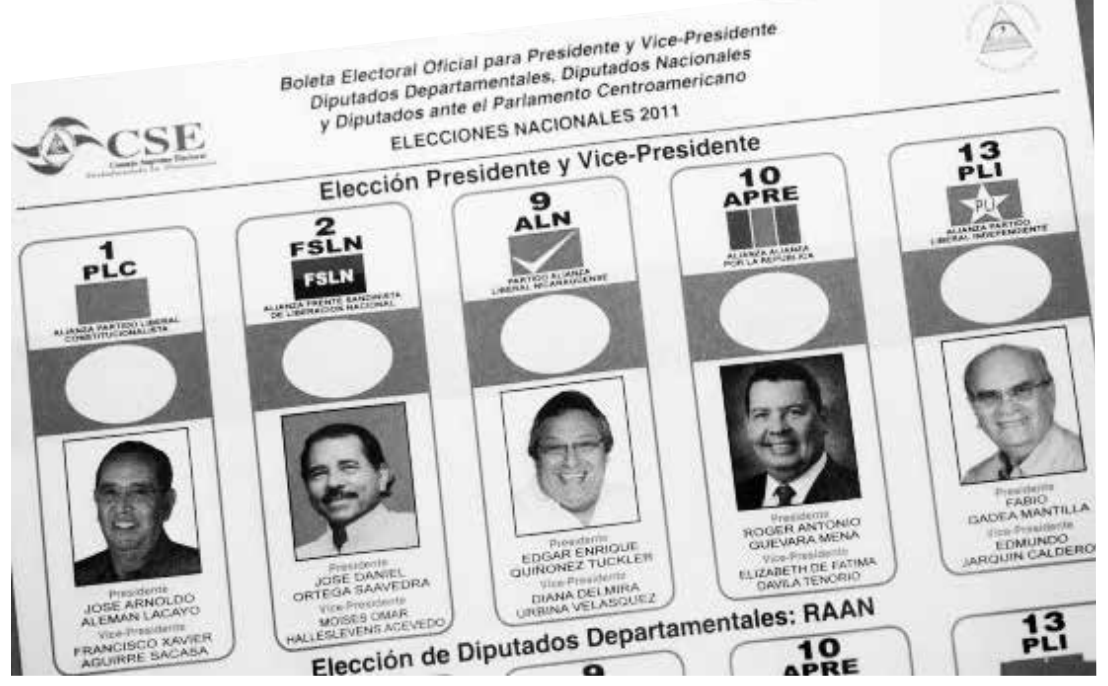

mando de autoridades más allá de lo establecido por la norma y costumbre de sucesión en los mandos policiales. Asimismo, ha habido quejas de que la fuerza pública ha permitido o dejado sin sanción el uso de la violencia por grupos civiles irregulares.

Fricciones en el Área Social.- Como reflejo de las agudas pugnas políticas, los partidos que han llegado al gobierno han tendido a poner una línea divisoria entre leales y enemigos. Las instituciones y fundaciones que han experimentado algún tipo de acciones hostiles han sido en su orden: Las fundaciones sin fines de lucro (ONGs); la Jerarquía católica; algunas Cámaras empresariales; medios de Comunicación; y, más en el ámbito local, los organismos municipales. En el caso de las ONGs, en general, estas instituciones civiles son expresiones del derecho constitucional que garantiza a los ciudadanos asociarse libremente para perseguir el bien común y ser instancias de participación ciudadana. Sin embargo, muchas de estas organizaciones creadas masivamente después de abril de 1990, manifiestan ser percibidas y hostigadas por los gobiernos de turno como aliadas del partido contrario. Más tarde, se les percibe como competencia, ya sea de programas ministeriales o de las estructuras políticas de base del partido gobernante. Este tipo de fricción obstaculiza el potencial que las ONGs tienen para canalizar recursos de cooperación externa e interna hacia metas sociales que el gobierno solo no puede cumplir.

En resumen: La institucionalidad del país está alterada en áreas donde más inciden y compiten los intereses de los partidos por la hegemonía y donde predomina la confrontación y el disenso. Los poderes del Estado respecto de su integración, funcionamiento y legitimidad son los más afectados, si bien es en el Sistema Electoral donde la institucionalidad se presenta colapsada y con los más bajos niveles de legitimidad.

Contrariamente, en áreas como la económica, la existencia de acuerdos sostenidos entre gobierno, empresarios, trabajadores e instituciones financieras internacionales, ha asegurado funcionalidad y producido progresos que benefician a toda la ciudadanía. 
El problema generatriz de la disfuncionalidad institucional, parece residir en la persistencia de visiones divergentes y excluyentes entre los grandes actores políticos y sus liderazgos -incluyendo los medios de comunicación politizados--, que les ha impedido establecer una visión nacional compartida en función del bien común y el desarrollo nacional.

A falta de entendimientos, la política en Nicaragua parece limitarse a buscar los mejores recursos para continuar la guerra por otros medios. Se trata como el objetivo de toda guerra de "neutralizar al máximo las fuerzas del enemigo".

Las primeras víctimas de este tipo de guerra son las instituciones del país. Las instituciones se conforman por leyes, derechos de propiedad y tradiciones y costumbres que permiten el funcionamiento apropiado de una sociedad. Además, las instituciones estimulan, limitan o impiden a los individuos de una colectividad conseguir sus fines sociales. Cuando las instituciones son debilitadas y pierden funcionalidad, las relaciones políticas, económicas y culturales entre los miembros de una sociedad se ven alteradas y el país se estanca o retrocede.

\section{Hay salidas a problemas de la institucionalidad:}

Las fricciones centrales en los ámbitos institucionales se derivan de la ausencia de tradiciones de consenso entre los partidos políticos. Institucionalizar los mecanismos de negociación y búsquedas de acuerdos con interlocutores calificados, es la base para abordar y superar la crisis institucional actual.

De la misma forma en que el Ejecutivo ha logrado consensuar políticas y medidas que han dado resultados en el área económica, es factible extender acuerdos para recomponer la legitimidad de las principales instituciones del Estado, priorizando el nombramiento formal de todos los miembros de los poderes del Estado con cargos vencidos.

La Reforma del Sistema Electoral es una necesidad urgente. El Consejo Supremo Electoral actual ha perdido la capacidad y la credibilidad para que las elecciones periódicas de autoridades sean un instrumento eficaz para contribuir a la estabilidad y la paz de la república. Para subsanar la involución institucional sufrida por la autoridad electoral, se precisa dotar a este poder del Estado de independencia, idoneidad de sus funcionarios, transparencia en resultados electorales y amplitud para sumar otras alternativas electorales y ciudadanas a los comicios.

La débil tradición de consensos debe dar lugar a la búsqueda de una visión compartida sobre temas centrales: desarrollo económico, educación nacional, justicia y legalidad, garantías a la propiedad, fortalecimiento a institucionalidad de las fuerzas armadas; participación ciudadana, entre otros.

Octubre 2013

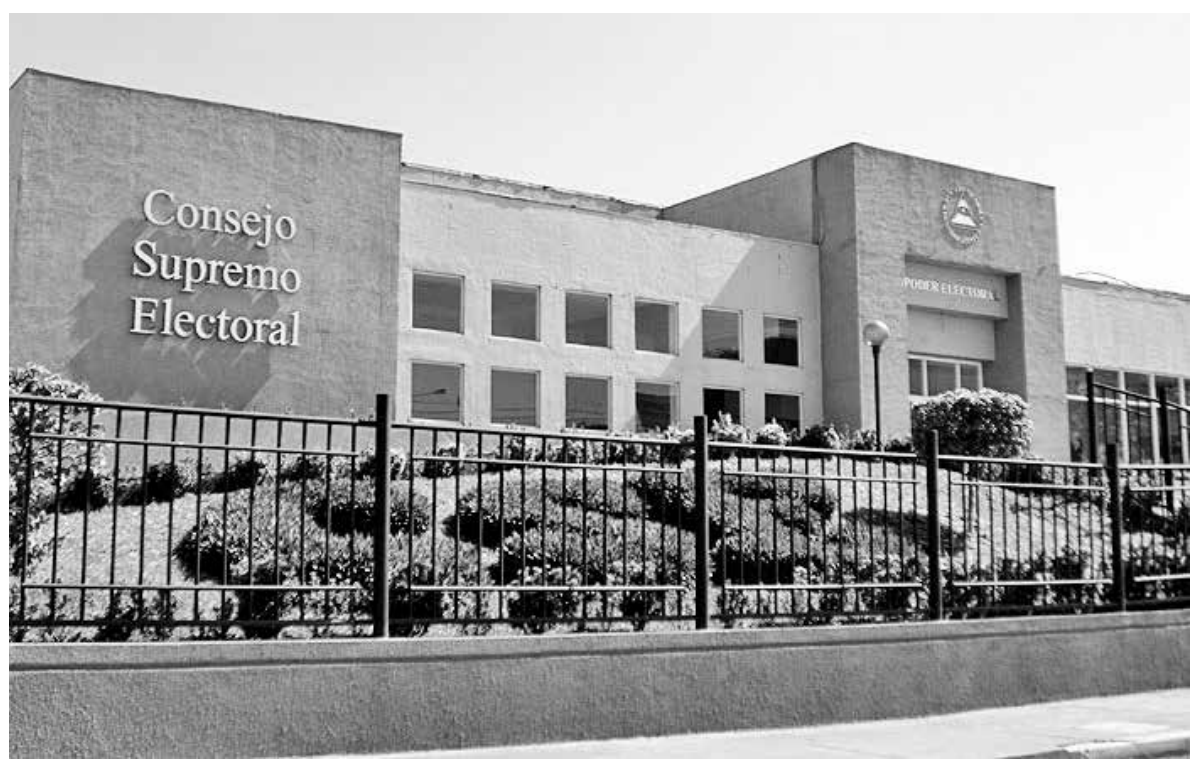

